\title{
Multi-criteria analysis of risks and phases in mining project
}

\author{
Dejan Bogdanović \\ Management department \\ University of Belgrade-Technical \\ faculty in Bor \\ Bor, Serbia \\ dbogdanovic@tfbor.bg.ac.rs
}

\author{
Ivan Jovanović \\ Management department \\ University of Belgrade-Technical \\ faculty in Bor \\ Bor, Serbia \\ ijovanovic@tfbor.bg.ac.rs
}

\author{
Anđelka Stojanović \\ Management department \\ University of Belgrade-Technical \\ faculty in Bor \\ Bor, Serbia \\ astojanovic@tfbor.bg.ac.rs
}

\begin{abstract}
The paper analyzes the most important groups of risks in the mining project. Risks have been identified and quantified by relevance and impact using the AHP method. After that, the ranking of the most important phases of the mining project from the aspect of risk was performed. Ranking is done by PROMETHEE multi-criteria decision making method. Here, the results obtained by the AHP method are used to rank the mining project phases, where the risks were used as the criteria and their coefficients as weight coefficients for ranking.
\end{abstract}

Keywords-Mining project, risk, multi-criteria analysis.

\section{INTRODUCTION}

Project management is a process for securing diverse sources and coordinating their activities with the goal of accumulating individual tasks in a multidisciplinary team effort to achieve the project's goal within the agreed time, budget and quality. However, the achieving the goal of the project also depends on the establishment of a consecutive model for project management. The essence of this model consists of seven interconnected components, which are: process, technology, organization, method, performance measures, organizational culture and people. These components must work together and be synchronized, as only, in this case, the organization functions well. The measure of success of the project manager is measured according to how well he synchronizes and harmonises these seven components.

Today, the essence of managing the project is in maintaining the balance in a "vicious triangle" - cost, quality and time of realization [1]. The required balance depends on many factors, and one of them is a good knowledge of the project's life cycle.

The project's life cycle represents the time period that elapsed from the idea to the completion of its realization. During this time period, the project goes through numerous phases, processes and activities. Accordingly, the life cycle of the project can be defined as a continuous process of overall project realization, consisting of several phases.

Mostly, the project life cycle is displayed through several global phases. The global phases of the project include a large number of sub-phases, processes and activities that are being realised in time.

Each project monitors the risks, and therefore they are specifically considered in the project planning phase. Risk is any unplanned event that can cause some damage to the project. Risks are divided into large, medium and small. Also, the probability of risks can be large, medium and small. It is very important for the project to identify all risky events in advance and to prepare certain measures to prevent them.

In this work, an integrated AHP-PROMETHEE method for the ranking of risks and project phases in the aspect of risks will be introduced. The AHP method will be used to analyze and rank the categories of risks and determine the criteria weight coefficients (groups of risks). Next, the PROMETHEE method will be used for final ranking of mining project's global phases in order to determine the riskiest one.

\section{LIFE CYCLE OF THE MINING PROJECT}

The life cycle of a mining project generally consists of four phases: exploration (F1), development (F2), operation (exploitation) (F3) and closure (F4) [2].

Exploration includes a many operations with the aim to discover, define and prove the profitability of future exploitation. Besides fieldwork, this phase also implies the creation of certain technical documentation. Because of its complexity, this phase lasts up to 10 years.

The second phase is a development that involves the creation of plans for the other stages that follow the research, as well as the activities that are necessary to prepare a mine for commercial exploitation. In other words, the aim of this project phase is to prepare the deposit for commercial production. The emphasis is on the construction of infrastructure, facilities and installations, as well as procurement of equipment, tools, etc. This phase lasts up to 10 years and is the most demanding from the aspect of an investment, so that it is the most costly in the mining project.

The exploitation phase is the only phase that provides revenue to the project. There is the exploitation of the ore. At this stage, the mining team takes the lead. This phase lasts the longest (up to 20 
years and more), although there are mines that are in operation for more than 200 years.

The last phase has the task of dismantling and removing installations and equipment from the mines, as well as to rehabilitate the land. This is a complex phase that usually lasts from 2 to 10 years.

\section{RISKS IN THE MINING PROJECT}

The mining project and its phases contain many uncertainties and risks that they carry. At each phase there are specific risks, although there are risks that accompany the project from the beginning to its completion. Mining risk management includes identification of various hazards or uncertainties [3]. Above all, new systematic and systematic approaches are needed that are able to constantly solve the problems that have arisen $[4,5]$. Proactive strategy of prevention is the best approach of systematic risk management [4].

The most common risks in mining project are as follows:

- a reduced quantity of the previously calculated geological reserves;

- the possibility of change of open pit limits;

- hydrogeological risks analysis of an underground mine or open pit;

- higher costs of operating than planned;

- the validity and the accuracy of the planned technological parameters;

- validation and the accuracy of selected ore process method;

- adequate equipment selection;

- construction, design and operation schedules;

- compliance with low,norms, regulations and standards;

- social risks

- environmental risks;

- analysis of expected cash-flow.

The above-mentioned risks can be divided into five categories [6] such as:

- operational (production) risks (R1) - failure of equipment, poor procedures, poor design solutions, security risks, etc. Zhang et al. [7] classifies operational risks in the following categories: security risks (injuries), planning risks, engineering risks (design, dimensioning, estimation of amount and of reserves and its quality, reliability and availability of equipment, data analysis, etc.), production risks and technological risks (selection of equipment, new equipment, etc.).

- financial and economic risks (R2) - access to capital, cost control, distribution of capital, prices of equipment, materials, stock prices, global demand, etc. These risks add uncertainty about the profitability of the mining project.

- political and legal risks (R3) - political problems, globalization, bureaucracy, gaps and differences between regulations, changes in regulations and laws, etc.

- environmental risks (R4) - operational phase (water pollution, excessive noise, atmospheric pollution, ore waste, dust, radiation, etc.) and the closing phase (long-term radiation effects, chemical products, ore waste, etc.).

- risks related to occupational health and safety (R5) - risks of accidents and occupational diseases (mining equipment, working conditions, natural phenomena, mining works, gallery collapse, etc.) The most influential factors of this risk are mechanical factors (equipment, cleaning and maintenance), electrical factors (electrical equipment and electrical energy sources), physical environments (dust, vibration, noise and humidity), social and human factors (incompetence, uncertain behavior) and working methods (organization of work, team management, planning and work).

\section{RANKING OF RisKS IN THE MINING PROJECT}

Ranking of risks categories was done using the AHP method. AHP is a quantitative technique that decomposes a compound decision problem into a multidimensional hierarchical structure of main goal, criteria, and alternatives. It calculates the impact of criteria, compares alternatives with respect to each criteria and calcultes the ranking of alternatives.

The ranking is done through a comparison matrix. This comparison is based on a scale of 1 to 9 [8] Tables I. and II. The results of the ranking are given in Table III. Criterium Decision Plus software was used for calculation.

TABLE I. COMPARASION SCALE

\begin{tabular}{|l|c|}
\hline \multicolumn{1}{|c|}{ Verbal Judgement } & Numerical Rating \\
\hline Equally preferred & 1 \\
\hline Moderately preferred & 3 \\
\hline Strongly preferred & 5 \\
\hline Very strongly preferred & 7 \\
\hline Extremely preferred & 9 \\
\hline \multicolumn{2}{|c|}{$2,4,6$ and 8 are intermediate values } \\
\hline
\end{tabular}

TABLE II. COMPARASION MATRIX

\begin{tabular}{|l|c|c|c|c|c|}
\hline Risk & R1 & R2 & R3 & R4 & R5 \\
\hline R1 & 1 & 1 & 6 & 3 & 3 \\
\hline R2 & & 1 & 5 & 3 & 3 \\
\hline R3 & & & 1 & $1 / 4$ & $1 / 2$ \\
\hline R4 & & & & 1 & 1 \\
\hline R5 & & & & & 1 \\
\hline
\end{tabular}


TABLE III. COMPARASION MATRIX

\begin{tabular}{|c|c|c|c|c|c|}
\hline Risk Categories & R1 & R2 & R3 & R4 & R5 \\
\hline Coefficient weight & 0,351 & 0,340 & 0,054 & 0,138 & 0,117 \\
\hline Consistency ratio & \multicolumn{5}{|c|}{$0,016<0,1$} \\
\hline
\end{tabular}

The results show that the riskiest category is R1 operational (production) risks. These are the most complex risks and last longer, along with financial and economic risks (R2), which are in the second place. Financial and economic risks are the most unstable risks that most contribute to the uncertainty of the mining project. In third place are the environmental risks (R4). Each mining project has a major impact on the environment, which can last for decades after closing the mine. On the fourth place are the occupational health and safety risks (R5). The mining project is one of the most difficult and most dangerous projects in terms of safety and health at work. The last was a political and legal risk (R3), which in our conditions can least damage to the project.

\section{RANKING OF PHASES OF THE Mining ProJect REGARDING THE RISKS}

Ranking of the most important phases of the mining project was performed by the PROMETHEE method for multi-criteria decision making. PROMETHEE is a ranking method for the set of alternatives [9]. This method first defines the corresponding preference function. The preference function shows how one alternative is relatively ranked to another one and translates the deviation between the evaluations of two samples on a single parameter - a preference degree. The PROMETHEE method has six preference functions with different specific shapes. Each shape dependens on two thresholds, Q and P. Q is an threshold wich indicates the largest deviation that is considered negligible. The preference threshold $\mathrm{P}$ indicates the smallest deviation that is considered as decisive. Here, Q cannot be bigger than $\mathrm{P}$. $\mathrm{S}$ represents the Gaussian threshold (middle value) that is only used with the Gaussian preference function.

The PROMETHEE method performes ranking by calculating the positive - input flow $\left(\Phi^{+}\right)$and the negative - output flow $\left(\Phi^{-}\right)$for each alternative according to the calculated coefficient weight of each criteria. The difference between the positive and the negative flows represents the net flow $(\Phi)$ is base for the complete ranking of alternatives. The best ranked alternative is one wich have the highest net flow value.

In this calculation by PROMETHEE method are used previous AHP analysis results, whereby the risks ae considered as criteria, and their value as the weight coefficients for the calculation. This way, it is possible to get a higher quality of the results of the ranking.

Based on the evaluation criteria (risk categories), phases of the mining project are evaluated, by forming the evaluation matrix. All criteria (risk categories) have a qualitative structure that cannot be accurately measured (an uncertain structure). Accordingly, the criteria are expressed on qualitative scale. The qualitative evaluation is done by an experts using a 5point scale - Table IV. Numerical value 1 represents the best category with very small risk, and numerical value 5 is the worst category with very high risk.

TABLE IV. Qualitative ScAlE

\begin{tabular}{|c|c|c|c|c|c|}
\hline $\begin{array}{c}\text { Qualitative } \\
\text { Value }\end{array}$ & $\begin{array}{c}\text { Very } \\
\text { small } \\
\text { risk }\end{array}$ & $\begin{array}{c}\text { Small } \\
\text { risk }\end{array}$ & $\begin{array}{c}\text { Avera } \\
\text { ge risk }\end{array}$ & $\begin{array}{c}\text { High } \\
\text { risk }\end{array}$ & $\begin{array}{c}\text { Very } \\
\text { high } \\
\text { risk }\end{array}$ \\
\hline $\begin{array}{c}\text { Numerical } \\
\text { Value }\end{array}$ & 1 & 2 & 3 & 4 & 5 \\
\hline
\end{tabular}

The evaluation matrix is given in Table $\mathrm{V}$.

TABLE V. EVALUATION MATRIX

\begin{tabular}{|c|c|c|c|c|c|}
\hline Criteria & R1 & R2 & R3 & R4 & R5 \\
\hline Max/min & Max & Max & Max & Max & Max \\
\hline $\begin{array}{c}\text { Coefficient } \\
\text { weight }\end{array}$ & 0,351 & 0,340 & 0,054 & 0,138 & 0,117 \\
\hline $\begin{array}{c}\text { Preference } \\
\text { function }\end{array}$ & Level & Level & Level & Level & Level \\
\hline F1 & 2 & 2 & 3 & 2 & 2 \\
\hline F2 & 4 & 3 & 4 & 3 & 4 \\
\hline F3 & 5 & 5 & 3 & 5 & 5 \\
\hline F4 & 3 & 3 & 4 & 4 & 3 \\
\hline
\end{tabular}

In the next step, the mining project phases are evaluated using the Decision Lab software. Table VI. shows the positive flow $(\varphi+)$, negative flow $\left(\varphi^{-}\right)$and net flow $(\varphi)$ values.

TABLE VI. EVALUATION MATRIX

\begin{tabular}{|c|c|c|c|}
\hline & $\boldsymbol{\Phi}^{+}$ & $\boldsymbol{\Phi}^{-}$ & $\boldsymbol{\Phi}$ \\
\hline F1 & 0,0000 & 0,4163 & $-0,4163$ \\
\hline F2 & 0,0780 & 0,0797 & $-0,0017$ \\
\hline F3 & 0,5297 & 0,0000 & 0,5297 \\
\hline F4 & 0,0230 & 0,1347 & $-0,1117$ \\
\hline
\end{tabular}

The riskiest alternative (phase of mining project) is determined by PROMETHEE II who performs complete ranking (Fig. 1). In this process the net flow values from the last column of Table VI. are used.

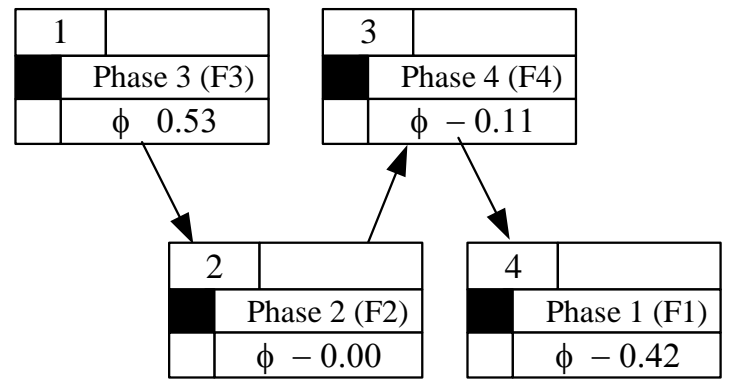

Fig. 1. PROMETHEE II complete ranking of mining project phases (Decision Lab 2000) 
Exploitation is the most complex phase of realization of a mining project that employs the largest number of resources, a large number of workers, many activities, etc., and it is accompanied by uncertainty about finances and cost-effectiveness. In the second place is the development that is the most complex phase of the project after the exploitation. This phase demands the largest investment in infrastructure and equipment, a large number of participants are involved, with the success uncertainty that of the project. Closure phase is in third place regarding the risk. Apart from the complexity of dismantling equipment and devices and their dislocation from the mines, the greatest complexity and risk is the remediation of the consequences of mining rehabilitation of the land. The greatest risks are related to the environment. The least risky phase in the mining project is exploration. Here the greatest risks are related to the estimation of quantity and quality of ore reserves.

\section{CONCLUSION}

In this paper, the multi-criteria methods for risk ranking, as well as the phase of the mining project from the aspect of risk, were applied. The AHP method was used to rank the risk categories and the PROMETHEE method for ranking the project phases regarding risks. Results obtained by the AHP method were used in the PROMETHEE method, which provides quality ranking results.

Consequently, on the basis of the obtained results, it was shown that the highest risk category is R1 operational (production) risks followed by financial and economic risks (R2), environmental risks (R4), occupational health and safety risks (R5) and political and legal risks (R3).

The riskiest phase of the mining project is the exploitation phase, followed by development, closure and exploration phase.

\section{ACKNOWLEDGEMENT}

Research funded by Serbian Ministry of Education and Technological Development as part of the project No.: TR-34023.

The authors also feel indebted to the company Visual Decision Inc. Montreal, Canada, for providing the software package Decision Lab 2000 free of charge.

\section{REFERENCES}

[1] P. Jovanovic, Project Management, (srb. Upravljanje projektom), Faculty of organizational sciences, Belgrade, 1995.

[2] A. Badri, S. Nadeau, and A. Gbodossou, "A mining project is a field of risk:a systematic and preliminary portrait of mining risks", Int. J. Saf. Secur. Eng., vol. 2(2), 2012, pp. 145-166.

[3] S. Schafrik, and V. Kazakidis, "Due diligence in mine feasibility studies for the assessment of social risk", Int. J. Min. Reclam. Env., vol. 25(1), 2011, pp. 86-101.

[4] M. Orsulak, V. Kecojevic, L. Grayson, and A. Nieto, "Risk assessment of safety violations for coal mines", Int. J. Min. Reclam. Env., vol. 55(2), 2009, pp. 119-130.

[5] S. Radosavljevic, N. Lilic, S. Curcic, and M. Radosavljevic, "Risk assessment and managing technical systems in case of mining industry", Stroj. Vestn.-J. Mech. E., vol. 24(3), 2010, pp. 244-254.

[6] Ernst, and Young, Attitudes to Risk and the Global Mining Sector, 2007.

[7] J. Zhang, C. Tian, W. Fang, and N. Zhang, "Assessment on operational risk in power grid enterprises based on variable weight fuzzy evaluation", International Conference on Energy and Environment Technology, ICEET 2009, vol. 2, 2009, pp. 92-95.

[8] T. L. Saaty, The Analytical Hierarchy Process, New York: McGraw-Hill, 1980

[9] J. P. Brans, B. Mareschal, and P. H. Vincke, PROMETHEE: A New Family of Outranking Methods in Multi-Criteria Analysis, Amsterdam: Operational Research, North-Holland, 1984. 